\title{
AERODYNAMIC SURFACE ROUGHNESS LENGTH OF BAGHDAD CITY
}

\author{
Monim H. Al-Jiboori and Aqeel G. Al-Draji \\ Department of Atmospheric Sciences, College of Sciences, Al-Mustansiriya University.
}

\begin{abstract}
A field study carried out to calculate the displacement height, $Z_{d}$, and roughness length, $Z_{0}$, for Baghdad city according to several commonly standard criterions. Meteorological equipments such as anemometer, wind vane and thermometer were used to observe wind speed, wind direction and air temperature at two levels of 15 and $20 \mathrm{~m}$. The results show that large variations in $Z_{d}$ and $Z_{0}$ depend strongly on roughness element height, wind direction and the changes in the upwind fetch. Also, Baghdad city is classified as medium density and urban surface according to the values of measured $\mathrm{Z}_{\mathrm{d}}$ and $\mathrm{Z}_{0}$.
\end{abstract}

Keywords: Roughness length, Displacement height, Richardson number, Urban surface, Logarithmic wind equation.

\section{Introduction}

The surface roughness length, $\mathrm{Z}_{0}$, is fundamental concept presented in numerous textbooks on fluid mechanics, dynamic meteorology and physical oceanography. It is also a key parameter to describe the aerodynamic characteristics of homogeneous and nonhomogeneous surfaces. Originally, $\mathrm{Z}_{0}$ is defined as the height above the surface at which wind speed goes to zero if the turbulent layer extended to completely to the ground. The $\mathrm{Z}_{0}$-values vary from about $0.0001 \mathrm{~m}$ over ice or water surfaces to several meters over urban areas, mountainous areas or irregular woods illustrating that $Z_{0}$ is a measure of how efficiently momentum can be transferred to the ground at a given wind speed [1].

Surely roughness elements (e. g. buildings for residences and companies, and trees) resulting from urbanization largely contribute in reducing wind speed in urban areas. Thus, accurate knowledge of the surface roughness parameters, which represent geometric characteristics of the surface, is required in many meteorological and engineering applications including numerical weather prediction, air pollution and climate modelling. The calculation of surface roughness is an initial feature to determine mass and energy exchanges between the land surface and the atmosphere.

There are several methods to determine $\mathrm{Z}_{0}$; some of them are based on the morphology and spatial arrangement of surface roughness elements. These methods were used by several researches such as Lettau [2], Bottema [3] and Grimmond and Oke [4] for calculating surface roughness characteristics over urban areas. They do have the disadvantage that most are based on empirical relations derived from wind tunnel work that concern constant flows over simplified regularly arrays of roughness elements. The another methods require observations of wind speed at least at one level such as the studies carried out by Beljaars [5] (using slow-response data measured by routine anemometers) and Martano [6] (using fastresponse data measured by sonic anemometers) over various surfaces. Although latter methods have disadvantages in obtaining and operating a field site, they are better whereas the characteristics of the surface do not need to be specified [4].

The roughness lengths were calculated for most world cities to determine the surface type (e.g., rural, suburban or urban) and its density (e.g., low, medium or high). Unfortunately, there were no studies that describe the aerodynamic surface of central Baghdad city. In this study, we present some of the results of experiment conducted in the area of Bab AlMhadham [7]. This experiment designed to calculate $\mathrm{Z}_{0}$ dependent on wind observations under neutral conditions using the standard criteria reported in the section 4. 


\section{Calculation of roughness parameters 1. Surface roughness length}

The vertical wind profile under neutral conditions at some distance above the roughness elements is usually well approximated by [1]

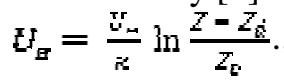

where $U_{Z}$ is the wind speed at height $Z, U_{*}$ is the friction velocity, $Z_{d}$ is the displacement height defined in the next subsection and $\kappa$ is the von Krámán (here taken to be 0.4 [1]). To calculate $\mathrm{Z}_{0}$, rearrange Eq. (1)

$$
Z_{\mathrm{a}}=\left(z-Z_{a}\right) \operatorname{EXP}\left(-\frac{Z_{z} z}{Z_{u}}\right)
$$

It is found that the ratio between the standard deviation of the wind speed, $\sigma_{\mathrm{U}}$, and $\mathrm{U}_{*}$ $\left(\varnothing_{U}=\sigma_{U} / U_{*}\right)$ is constant under neutral conditions [1], so Eq. (2) becomes

$$
Z_{\mathrm{Q}}=\left(Z-Z_{\mathrm{Z}}\right) \operatorname{EXP}\left(-\frac{U_{\mathrm{Z}} \mathrm{vi}_{\mathrm{v}}}{\Omega_{\mathrm{v}}}\right)
$$

The observational evident shows that the value of $\emptyset_{U}$ is from 2.4 to 2.5 with a mean value of 2.4 for urban and rural sites [1].

\section{Displacement height}

Over land, if the individual roughness elements are packed very closely together, then the top of those elements begins to form like a displaced surface. The height of this new surface calls the displacement height, $Z_{d}$, which is located above the actual ground. To determine $Z_{0}$, the value of $Z_{d}$ can be obtained using the expression below intended explicitly for urban area [3].

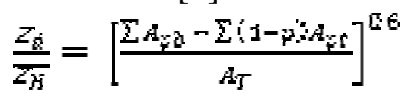

where $\overline{Z_{H}}=\left(\Sigma Z_{H} / N\right)$ is the mean geometric height of buildings and trees with $\mathrm{N}$ the total number of the elements, $A_{p b}$ and $A_{p t}$ are the plan areas of buildings and trees respectively, $\mathrm{A}_{\mathrm{T}}$ is the total area and $\mathrm{p}$ is the porosity of trees, which is set to 0.6 in winter, 0.4 in autumn and spring, and 0.2 in summer [3, 4].

\section{Standard criterions to obtain $Z_{0}$}

More than sixty studies that provide anemometric based estimates of roughness lengths in cities were reviewed by Grimmond and Oke [4]. They assessed each study by applying the following criteria and then excluded most of them because the $Z_{d}$ had not been included:
1. Site characteristics. The site should be relative flat and the fetch of the upstream distance of flow over surface of similar roughness is sufficient.

2. Tower construction. It is slender and open enough to avoid wake effects near the instruments.

3. Measurement heights. Lowest observational level must be greater than $\mathbf{1 . 5} \overline{Z_{H}}$ [8] and highest level must be inside the internal boundary layer of the surface of concern.

4. Instrumentation. Instruments possess appropriate response characteristics for wind measurements, which are averaged over a sufficient time period.

5. Atmospheric stability. Data under neutral conditions or stability corrections for nonneutral conditions should be used.

6. Inclusion of $\mathrm{Z}_{\mathrm{d}}$. Analysis to obtain roughness length must incorporate $Z_{d}$.

\section{Experimental design}

\section{The site description}

The analyzed data in the present study are obtained by installing meteorological instruments in an urban area called $\mathrm{Bab}$ Al-Mhadham located in Baghdad city $\left(33.14^{\circ} \mathrm{N}, 44.2^{\circ} \mathrm{E}\right.$ and elevation of $31.7 \mathrm{~m}$ above mean sea level). Tigris River is around the area from the south to the north-west with a distance about $1 \mathrm{~km}$ (see Fig. (1)). The area surrounding the measurement site consists mainly of various roughness elements such as low houses with $6 \mathrm{~m}$ height for residences, tall buildings with $20 \mathrm{~m}$ height for governmental offices, hospitals and commercial companies, and various trees with a height between 5 and $15 \mathrm{~m}$ (mainly date, pine and some olive trees).

Within a circle of radius of about $800 \mathrm{~m}$, instruments were set up on the roofs belonging to Engineering College, Al-Mustansiriya University. A few tall buildings are located in the vicinity of the experimental site from the south to the west-south. Typically buildings and trees cover about $30 \%$ and $15 \%$ of the total surface of the circle, respectively. We divided this circle to sixteen directional sectors of $22.5^{\circ}$ as illustrated in Fig. (1). Oblique photographs of each sector are presented in Fig. (2). The urban fetch extended from the site to a rural/urban border was estimated for each sector from a Baghdad map and is 
presented in Table (1). The mean geometric height (including buildings, trees and other cover land) is also calculated for each sector and reported in the same table.

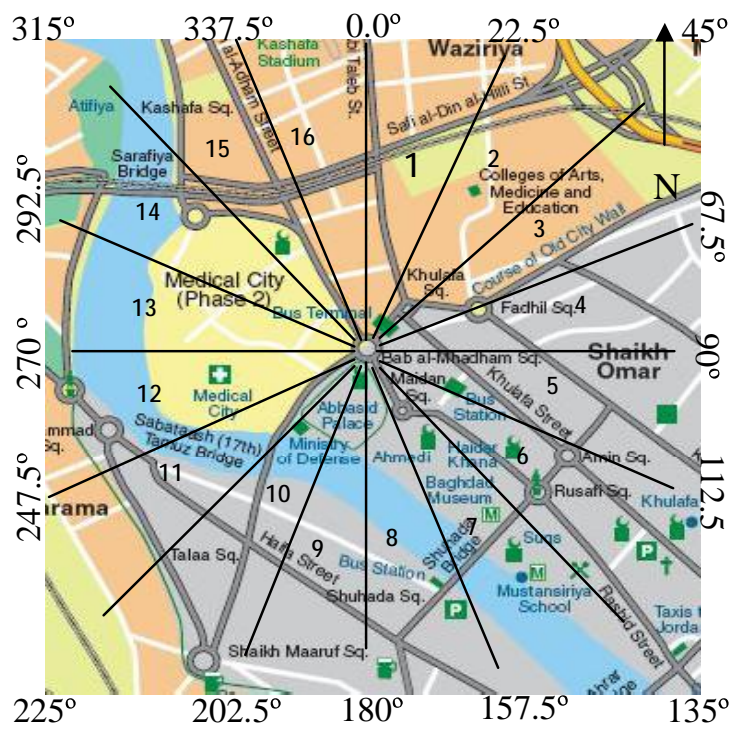

Fig. (1): Part of Baghdad map, especially areas around Bab Al-Mhadham.

Table (1)

Site features of the observation field.

\begin{tabular}{|c|c|c||c||}
\hline $\begin{array}{c}\text { Sec. } \\
\text { no. }\end{array}$ & Direction $\left(^{\left.{ }^{\circ}\right)}\right.$ & $\begin{array}{c}\text { Fetch } \\
(\mathbf{k m})\end{array}$ & $\overline{\mathbf{Z}_{\boldsymbol{H}}}(\mathbf{m})$ \\
\hline 1 & $0.0-22.5$ & 7.5 & 7.5 \\
\hline \hline 2 & $22.6-45.0$ & 6.3 & 8.8 \\
\hline 3 & $46.0-68.5$ & 9.3 & 13.2 \\
\hline \hline 4 & $68.6-90.0$ & 10.0 & 9.2 \\
\hline 5 & $90.0-112.5$ & 12.5 & 5.5 \\
\hline 6 & $112.6-135.0$ & 11.3 & 6.5 \\
\hline 7 & $135.0-175.5$ & 17.5 & 7.8 \\
\hline \hline 8 & $175.6-180.0$ & 13.7 & 10.5 \\
\hline \hline 9 & $181.0-202.5$ & 15.0 & 11.0 \\
\hline \hline 10 & $202.6-225.0$ & 13.7 & 19.5 \\
\hline 11 & $226.0-247.5$ & 12.5 & 14.0 \\
\hline \hline 12 & $247.6-270.0$ & 10.7 & 8.5 \\
\hline 13 & $271.0-292.5$ & 11.3 & 7.2 \\
\hline \hline 14 & $292.6-315.0$ & 5.6 & 7.5 \\
\hline 15 & $316.0-337.5$ & 4.5 & 7.3 \\
\hline \hline 16 & $337.6-360.0$ & 4.5 & 7.1 \\
\hline
\end{tabular}
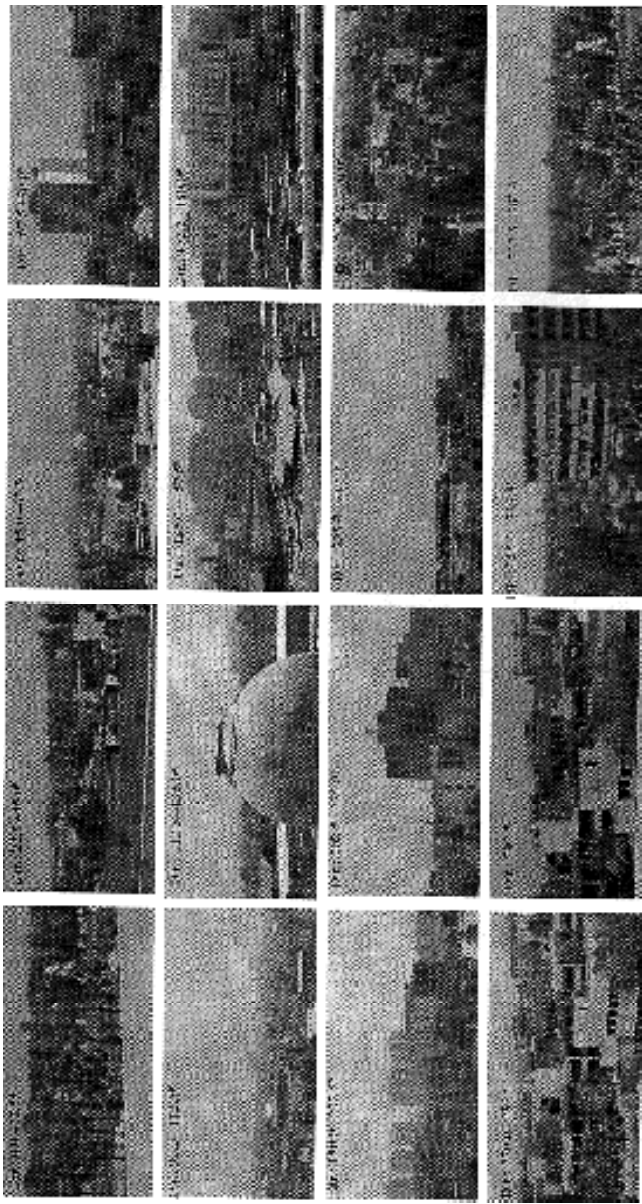

Fig. (2) : Photographs of each sector surrounding the studying site.

\section{Instrumentation and data}

In order to determine the atmospheric stability and roughness lengths, two systems of classical slow-response instruments such as three-cup anemometer, thermometer and wind vane were mounted on a short mast on the roof of 15- and 20-m buildings. They measure wind speed, temperature and wind direction at each level, respectively. These measurement heights follow the criteria \#3 if the average of $\mathrm{Z}_{\mathrm{H}}$ across all directional sectors is $9 \mathrm{~m}$ (level 15 or

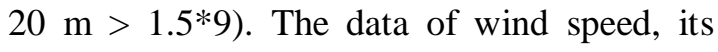
direction and temperature were observed at the two heights above and at the same time for the period from 4 to 20 April 2006. These measurements were taken at the sunset times from 1600 to 2000 local time with length of $20 \mathrm{~min}$ and recorded each minute. We select these times to get more possible data under neutral conditions where the atmosphere is in transition case. 
Wind data obtained were compared with those obtained from other type (Demo-6) belonging to Iraqi meteorological organization as shown in Fig. 3. The solid line is the best fit to these data which is represented by the expression

$$
\tau_{E}=1.8 \mathrm{~L}-9.4
$$

Therefore we corrected all the original data measured at the two heights using this equation.

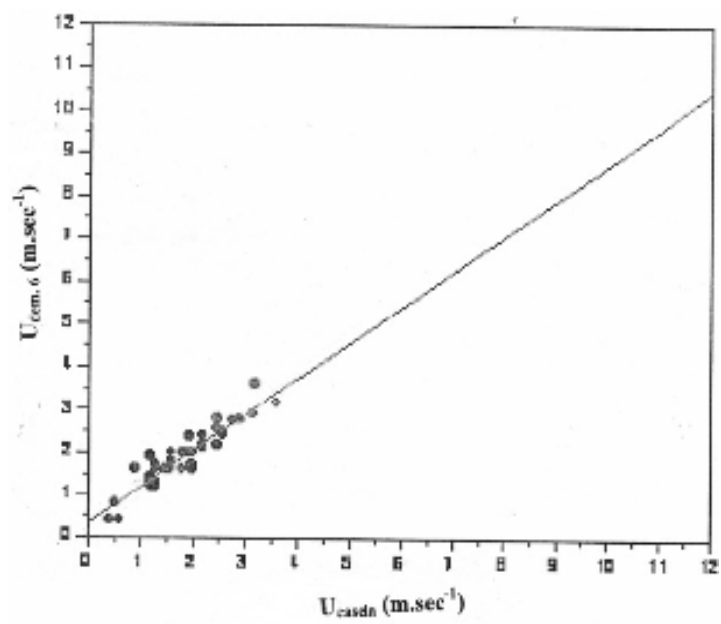

Fig. (3): Comparison between wind speed values obtained from three-cup (Casela type) and (Demo-6 type) anemometers. Solid line is represented by expression (5).

The atmospheric stability was determined by calculating Richardson number given as [1]

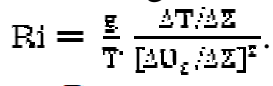

where $\bar{T}$ is the mean temperature and $\mathrm{g}$ is the acceleration of gravity due to the earth. Total number of observational runs was more than 65 , but only 25 runs under neutral or near neutral conditions with $\mathrm{Ri}$ between 0.01 and 0.01 were used for the analysis of this study. It should be noted that there is no any runs under stable conditions because of the heat convection particularly the vertical heat flux due to the ground heating. Neutral stratification occurs under strong wind conditions. The ratio between corrected wind speed at 20 and $15 \mathrm{~m}$ was calculated and plotted versus Ri as shown in Fig. (4). Their ratio increases linearly when $\mathrm{Ri}$ approaches zero. In other words, wind values at level $20 \mathrm{~m}$ are larger than those at $15 \mathrm{~m}$. Ratio values were fitted by the following expression using the Origin6.1 software:

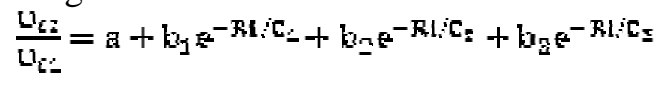

where $a, b_{1}, b_{2}, b_{3}, C_{1}, C_{2}$ and $C_{3}$ are empirical constants. Their values derived from experimental data for $\mathrm{Ri}$ and $\mathrm{Uc}_{2} / \mathrm{Uc}_{1}$ were $0.05,22.41 .95,0.28,-0.01,1.7$ and 5.4, respectively.

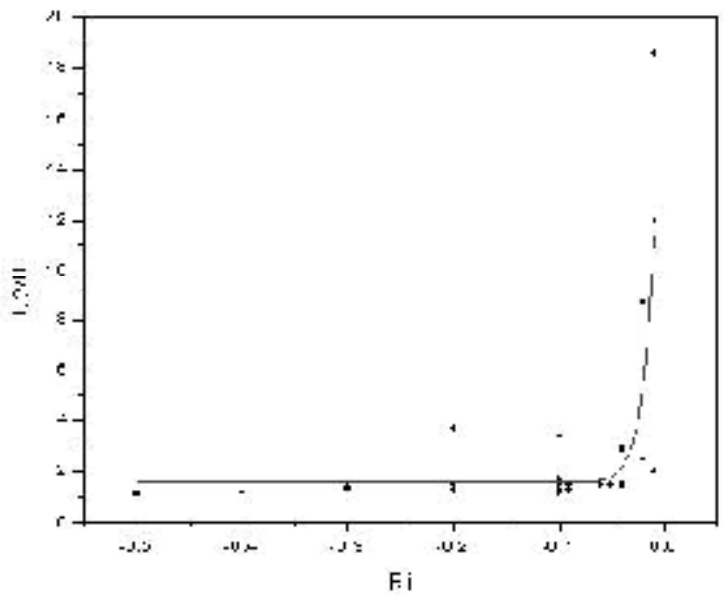

Fig. (4): Ratios of corrected wind speed at levels 15 and $20 \mathrm{~m}$ versus Ri. Solid line is given by Eq. (7).

\section{Results and Discussion}

\section{Displacement length}

The calculation of $Z_{d}$ is important in determining $Z_{0}$, so geometric heights of roughness elements and its blocking plan areas required to execute Eq. (4) were estimated for each sector. The values of $Z_{d}$ and $\overline{Z_{\boldsymbol{F}}}$ for all directional sectors are presented in Fig. (5). They have almost similar trend across all directions with large values for $\overline{\mathbf{Z}_{\mathbf{r}}}$. In this work, the values of $Z_{d}$ are about two thirds of the values of $\overline{E_{F}}$. This result can be enhanced by the rule of thumb mentioned in (1).

where as $\mathrm{Z}_{\mathrm{d}}$ is $70-80 \%$ of $\mathrm{Z}_{\mathrm{H}}$. 


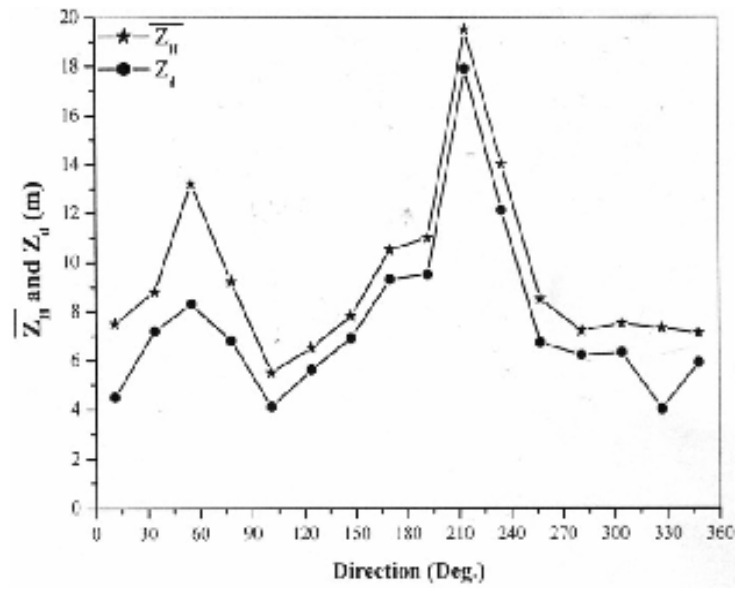

Fig. (5): Displacement, $Z_{d}$, and mean geometric, $Z_{H}$, heights of roughness elements for each sector.

As can be shown from Fig. (5) and Fig. (2), large values of $Z_{d}$ and $\overline{Z_{f i}}$ are in sector $10\left(202-225^{\circ}\right)$, while lower values are in sector $5\left(90-112^{\circ}\right)$. Across all directions the $Z_{d}$ and $\overline{Z_{\mathrm{H}}}$ values are in the range of $4-17.9 \mathrm{~m}$ and $5.5-19.5 \mathrm{~m}$ and their average values are 9.5 and $7.5 \mathrm{~m}$, respectively. These values fall in the reasonable ranges which suggest medium height and density for urban surface [8]. According to a simple rule of thumb, which holds that $Z_{d}$ is simply related to the $Z_{H}$, i.e. $Z_{d}=f_{d}=\overline{Z_{H}}$ with $f_{d}$ is empirical coefficient derived from observations. In this work, $f_{d} \sim 0.79$ which is close to 0.7 given by [4] for the real cities. In other way, we can use mean plan area index, $\overline{\lambda_{\mathrm{p}}}=\overline{A_{\mathrm{p}}} / \mathrm{A}_{\mathrm{T}}$ (where $\overline{A_{\mathrm{p}}}$ is the mean plan area), to measure the surface properties in Baghdad city. The value of $\overline{A_{p}}$ around the site was found to be 0.60 as reported by [9]. This means that the surface of Baghdad city is medium density and the flow is skim according to the tables given by [4]. This reference showed that this kind of the surface consists of residential buildings and trees closely packed and of similar height, and narrow street canyons (e.g. old town centers; dense factories; schools; universities).

\section{Roughness length}

The values of $\mathrm{Z}_{0}$ were calculated from Eq. (3) with determining $\sigma_{U}$ from the data of 20 values for wind speed. During the measuring period, only six direction sectors were obtained. The number of runs, observed wind directions, $Z_{0}$ values for each measurement level, $\overline{\mathrm{Z}_{\mathrm{g}} / \mathrm{Z}_{\mathcal{H}}}$ and the surface density are tabulated in Table (2).

It is interesting in looking for inhomogenities in the urban surface for Baghdad city. Therefore the calculated values of $\mathrm{Z}_{0}$ with their respective sectors are plotted in Fig. (6a). It is obvious that inhomogenity in the horizontal surface is indicated from the large variation in the values of $Z_{0}$. Across all wind direction sectors, $Z_{0}$ values range from 0.7 to $1.7 \mathrm{~m}$ with mean value of $1.2 \pm 0.4 \mathrm{~m}$.

Table (2)

Values of $Z_{0}$ for each measurement level, their averages and surface density type.

\begin{tabular}{|c|c|c|c|c|c|c|}
\hline \multirow{2}{*}{$\begin{array}{c}\text { Sec. } \\
\text { no. }\end{array}$} & \multirow{2}{*}{$\begin{array}{c}\text { Runs } \\
\text { no. }\end{array}$} & \multicolumn{2}{|c|}{$\mathbf{Z}_{0}(\mathbf{m})$} & \multirow{2}{*}{$\begin{array}{l}\overline{Z_{0}} \\
\mathbf{m}\end{array}$} & \multirow{2}{*}{$\frac{z_{\mathrm{O}}}{z_{\mathrm{H}}}$} & \multirow{2}{*}{$\begin{array}{c}\text { Surface } \\
\text { type }\end{array}$} \\
\hline & & $\begin{array}{l}15 \\
\mathrm{~m}\end{array}$ & $\begin{array}{l}20 \\
\mathbf{m}\end{array}$ & & & \\
\hline 3 & 4 & 3.1 & 0.4 & 1.7 & 0.13 & Medium \\
\hline 7 & 10 & 2.1 & 0.3 & 1.2 & 0.15 & Medium \\
\hline 8 & 4 & 1.4 & 0.2 & 0.8 & 0.08 & High \\
\hline 14 & 28 & 0.5 & 1.0 & 0.7 & 0.09 & Medium \\
\hline 15 & 6 & 0.8 & 0.9 & 0.9 & 0.12 & Low \\
\hline 16 & 6 & 2.7 & 0.5 & 1.6 & 0.23 & Medium \\
\hline
\end{tabular}

From Fig. (6a), high roughness is in sector $3\left(45-65^{\circ}\right)$ and $16\left(338-360^{\circ}\right)$ which is identical to dense roughness elements with four floors (e.g. College of Arts and Institute of Management are about $200 \mathrm{~m}$ from the site) shown in the photographs for Fig. (2). Low roughness is in sector $14\left(293-315^{\circ}\right)$, in which there are schools with two floors located 200 $\mathrm{m}$ to the site. As shown from Table (2), generally, values of $Z_{0}$ at levels $15 \mathrm{~m}$ are larger than those at level $20 \mathrm{~m}$. The reason is that the 15-level is adjacent to the roofs of buildings. This means that airflow is affected by variation of the roughness elements around the site. Thus, to express the surface roughness of Baghdad, it should be incorporated the results for both heights as taking in average value. 


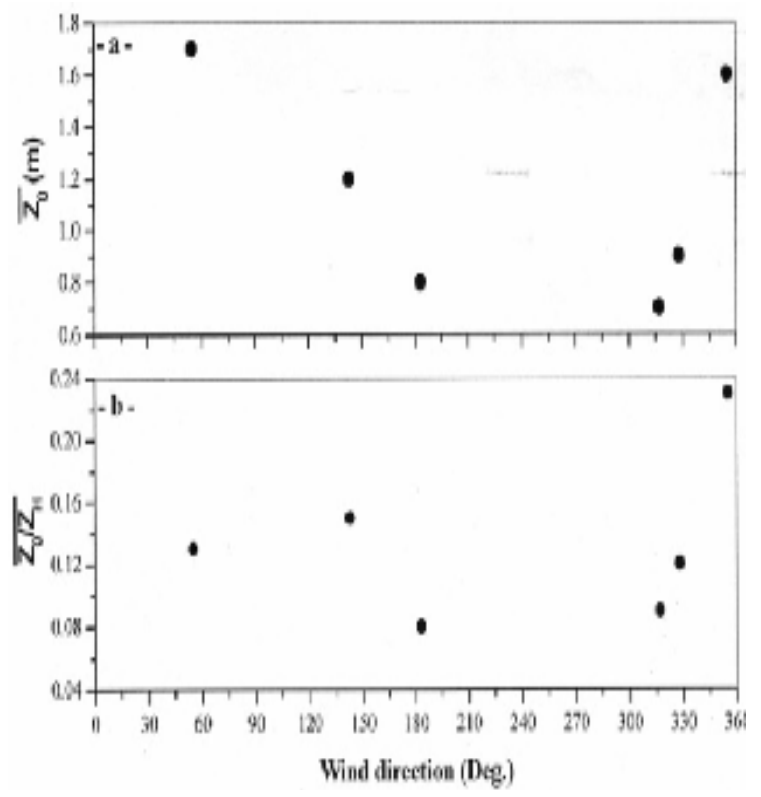

Fig. (6): (a) Roughness length, $Z_{0}$, and (b) height normalized $Z_{0} / Z_{H}$ as a function of wind direction for near-neutral and neutral data.

Considering the non-dimensional roughness length normalized with mean height $\overline{Z_{0} / Z_{H}}$ to support the description of the surface characteristics around the measurement site. This non-dimensional quantity ranges from 0.08 to 0.23 (see Fig. (6b)) with the average value of 0.13 , which is the same to that reported by [10] for crop and grass canopies, and larger than that suggested by [4]. Lower ratio is in sector $8\left(175-200^{\circ}\right)$ while higher ratio is in sector $16\left(350-360^{\circ}\right)$. These values agree reasonably with the nature of horizontal features shown in Fig. (2). From the range of $\mathrm{Z}_{0}$ values, 0.7-1.7 $\mathrm{m}$, one could be classified the central city of Baghdad as medium density according to the typical values reported in [8].

\section{Conclusions}

Based on the observations under near neutral conditions of wind speed, wind direction and temperature measured by the instruments of anemometer, wind vane and thermometer were analyzed to calculate surface roughness length of Baghdad city according to several standard criterions. These instruments were set up on short tower placed on the roofs of two buildings of 15 and $20 \mathrm{~m}$ at the location of Bab Al-Mhadham area which can be represented as the centre of Baghdad city. Before calculating $\mathrm{Z}_{0}, \mathrm{Z}_{\mathrm{d}}$ was calculated for sixteen directional sectors of $22.5^{\circ}$. Only six wind directions were obtained from the experiment study.

The main results can be summarized as follows:

1. Directional variations, elements variations and the changes in the upwind fetch influence the roughness lengths, so a single value of $Z_{0}$ cannot be assigned to an urban area.

2. The $\mathrm{Z}_{\mathrm{d}}$-values around the measurement site range from 4 to $17.9 \mathrm{~m}$ with mean value of $7.5 \mathrm{~m}$.

3. The $\mathrm{Z}_{0}$-values are in the range from 0.7 to $1.7 \mathrm{~m}$ with the average value of $1.2 \pm 0.4$.

4. Through $Z_{d^{-}}$and $Z_{0^{-}}$-values, Baghdad city is classified as medium density and urban area.

\section{References}

[1] H. A. Panofsky and J. A. Dutton, "Atmospheric Turbulence: Models and Methods for Engineering Applications", John Wiley and Sons, 1984, pp. 107-156.

[2] H. Lettau, "Note on Aerodynamic Roughness Parameter Estimation on the Basis of Roughness Element Description", J. Applied Meteorology, Vol. 8, 1969, pp. 828-832.

[3] M. Bottema, "Aerodynamic Roughness Parameters for Homogeneous Building Groups - Part 2: Results", Document SubMeso \#23, École Centrale de Nantes, France, 1995, pp. 80.

[4] C. S. Grimmond and T. R. Oke, "Aerodynamic Properties of Urban Areas Derived from Analysis of Surface Form", J. Applied Meteorology, Vol. 38, 1999, pp. 1262-1292.

[5] A. C. Beljaars, "The Measurement of Gustiness at Routine Wind Stations-A Review", Koninklijk Nederlands Meteorologish Instituut Scientific Report WR87-11, 1987, pp. 50.

[6] P. Martano, "Estimation of Surface Roughness Length and Displacement Height from Single Sonic Anemometer Data", J. Applied Meteorology, Vol. 39, 2000, pp. 708-715. 
[7] M. H. Al-Jiboori and A. G. Al-Draji, "Calculation of Surface Roughness Length for Baghdad Area Using Standard Criterions" M. Sc. Thesis, 2006, pp. 67.

[8] J. Wieringa, "Updating the Davenport Roughness Classification", J. of Wind Engineering and Industrial Aerodynamics, Vol. 41-44, 1992, pp. 357-368.

[9] C. S. Grimmond T. S. King, M. Roth and T. R. Oke, "Aerodynamic Roughness of Urban Areas Derived from Wind Observations", Boundary-Layer Meteorology, Vol. 89, 1998, pp. 1-24.

[10] M. R. Raupach, R. A. Antonia and S. Rajagopalan, "Rough Wall Turbulent Boundary Layer" Applied Mechanical Review, Vol. 44, 1991, pp. 1-25.

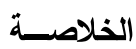

تم تتفيذ در اسة حقلية لحساب ارتفــاع الاز احسـة،

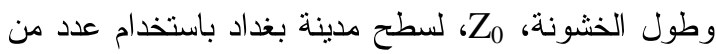

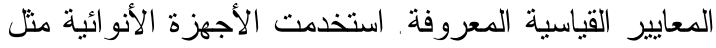

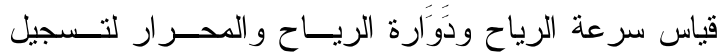

سرعة الرياح و اتجاهها ودرجات الحرارة عند الارتفــاعين

Zd 20 m و 15 m

و تعتمد بشدة على ارتفاع عنصر الخشونة واتجاه الرياح

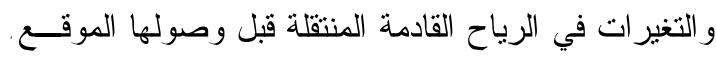

كذلك تم تصنيف سطح مدينة بغداد بإنه ذو كثافة متوســطة فئة

وحضري وفقاً الى قيَّم 